\title{
VEM AÍ NA GLOBO UMA NOVA PROGRAMAÇÃO
}

\section{Vem aí na Globo: the new show \\ Vem aí na Globo: una nueva programación}

\author{
Gabriel Souza \\ Doutorando do Programa de Pós-Graduação em Comunicação da Universidade Federal de Santa Maria. Inte- \\ grante do grupo da pesquisa Comunicação Televisual (COMTV). \\ E-mail: gabrields92@hotmail.com
}

\section{Maria Lília Dias de Castro}

Professora do Programa de Pós-Graduação em Comunicação da Universidade Federal de Santa Maria. Pós-doutora em comunicação pela Universidade de Paris III - Sorbonne Nouvelle. Coordenadora da pesquisa Comunicação Televisual (COMTV)

E-mail:mlilia@terra.com.br

RESUMO Este trabalho propõe examinar, por meio da semiótica discursiva, de inspiração europeia, e dos desdobramentos propostos por seus seguidores, o programa Vem Aína Globo 2013, transmitido pela Rede Globo, e refletir sobre as estratégias comunicativas e discursivas adotadas pela empresa ao utilizar novos e antigos programas para construir um produto televisual para divulgar a nova programação.

PALAVRAS-CHAVE Estratégia, Programação, Promocional, Rede Globo, Semiótica discursiva.

ABSTRACT This paper proposes to examine, through discursive semiotics, of European inspiration, and the developments proposed by its followers, Rede Globo's show Vem Ai na Globo 2013, and reflect on the communicative and discursive strategies adopted by the company when using new and old programs to build a televisual product to publicize the new program.

KEYWORDS Strategy, Programming, Promotional, Rede Globo, Discursive semiotics.

RESUMEN Este trabajo se propone examinar, a través de la semiótica discursiva, de inspiración europea, y los desarrollos propuestos por sus seguidores, el programa Vem Aína Globo 2013, de la Rede Globo, y reflexionar sobre las estrategias comunicativas y discursivas adoptadas por la empresa a usar programas nuevos y antiguos para construir un nuevo producto televisivo para dar a conocer la nueva programación.

PALABRAS CLAVE Estrategia, Programación, Promoción, Rede Globo, Semiótica discursiva. 


\section{CONSIDERAÇÕES PRELIMINARES}

Desde sua concepção, a televisão no Brasil, diferentemente de outros países em que predominam emissoras de televisão pública, surge como empresa comercial, o que requer a constante busca de aperfeiçoamento técnico, o investimento em novas tecnologias, a qualificação da equipe, a crescente e acirrada briga pela audiência. Essa condição leva as emissoras à adoção de estratégias que lhes permitam reiterar a programação, apoiar iniciativas de interesse social, desenvolver novos projetos, sempre com a preocupação de reforçar a própria marca. Assim, além de anunciantes externos, as emissoras assumem a posição de anunciantes dos próprios produtos.

A consequência natural é a preocupação sistemática da empresa de televisão de capitanear ações que agradem o telespectador, a fim de fortalecer e consolidar a força da própria emissora. Esse desafio constante resulta em novas estratégias de interpelação do público, com vistas a atrair atenção, a surpreender o telespectador para que ele consuma o produto televisual, o que, consequentemente, aumentará a audiência e trará resultados satisfatórios à emissora.

Dentro do amplo e diversificado universo de produção, merece destaque, neste estudo, um tipo específico de material: aquele construído com o objetivo de divulgar o conjunto dos programas que integram a grade anual de programação. Ao longo da última década, muitas foram as ações empreendidas pela Rede Globo com a finalidade precípua de divulgar a grade da emissora para os telespectadores e, em certa medida, de valorizar a própria empresa, assinalando claramente um movimento de autopromoção. Entre essas iniciativas estão comerciais, quadros e programas que perpassam anualmente a grade da emissora e que, por isso, constituem importante material de estudo.

Refletindo sobre esse tipo de produção midiática televisual nos dias de hoje, em que o telespectador se mostra mais exigente, a concorrência tem crescido significativamente e o universo das novas mídias concorre para desviar a atenção do público, como as emissoras de televisão vêm reagindo a esse novo cenário? Qual é a discussão central que essas produções reiteram? Que estratégias de comunicação com o público são trazidas? Como a produção anual pode fortalecer a grade da emissora? Quais são as estratégias discursivas predominantes?

Nessa medida, este estudo - partindo da hipótese de que, para atrair o telespectador, as emissoras de televisão, que funcionam como qualquer outra empresa comercial, estão sempre no limiar entre o reforço da oferta convencional e a aposta em produtos inovadores propõe examinar um tipo específico de produto: o programa Vem Aí na Globo 2013, realizado pela TV Globo, e assim refletir sobre as estratégias comunicativas e discursivas adotadas pela empresa nesse movimento simultâneo de proximidade com o telespectador e de fala de si mesma (autopromocionalidade).

\section{APORTE TEÓRICO-METODOLÓGICO}

A base teórica deste estudo fundamenta-se nas investigações da semiótica greimasiana, para procurar descrever e explicar o que o texto televisual Vem aí na Globo diz e como faz para dizer o que diz, ou seja, analisar discursivamente as articulações presentes no produto 
midiático (texto), compreendendo também os possíveis alargamentos, que constituem aquilo que os seguidores da teoria denominaram de textualidade.

Para a semiótica greimasiana, o texto é uma unidade de sentido, que, para ser interpretada, obedece a um percurso gerativo que parte do simples e abstrato e vai ao complexo e concreto. Em outras palavras, é uma sucessão de patamares, estabelecidos em três níveis - fundamental, narrativo e discursivo -, os quais se inter-relacionam para exprimir o sentido daquilo que está sendo dito.

O primeiro nível, conhecido como fundamental ou profundo, é o mais simples e está na base da construção do texto: é a instância que determina o mínimo de sentido do que vai ser produzido, ou seja, é onde se inicia o processo de significação. Nesse patamar, estrutura-se uma tensão preliminar, visto que todo texto põe em jogo dois valores distintos, a oposição semântica de base, como alegria vs tristeza, vida vs morte, liberdade vs dominação, partida vs retorno, entre outros.

O segundo nível, conhecido como narrativo, é a instância que identifica os elementos narrativos simples e as regularidades constantes. Nesse nível, os valores são assumidos pelos humanos, em movimentos de conjunção e disjunção com os objetos de valor, acarretando as transformações do enunciado, ocasionadas pela ação desses sujeitos. Greimas busca mostrar que o homem organiza aquilo que diz em uma estrutura que sempre se repete, e essa instância é conhecida como antropomorfização.

O terceiro nível, o discursivo, é a instância mais próxima da estrutura textual e, por conseguinte, a mais superficial: "as estruturas discursivas, menos profundas, são encarregadas de retomar as estruturas semióticas de superfície e de 'colocá-las em discurso', fazendo-as passar pela instância de enunciação” (Greimas; Courtés, 2013, p. 234). Aqui, os sujeitos do nível narrativo ganham nomes e tornam-se personagens (atores reais ou fictícios) do texto, ou seja, são revestidos de termos que lhes dão concretude. Nesse sentido, estão presentes os procedimentos de tematização, figurativização, actorialização, espacialização, temporalização e também de tonalização: "O processo de tonalização tem por tarefa a atribuição estratégica de um tom principal ao discurso produzido e sua articulação com outros tons a ele correlacionados” (Duarte, 2010, p. 241).

Dessa forma, a teoria semiótica constitui-se no apoio epistemológico para a discussão da tensão de base - inovação vs tradição - que permeia essa produção televisual, depois atualização pela ação do sujeito e manifestada no texto Vem Aí na Globo.

Para dar conta desse texto e do contexto em que ocorre, na perspectiva teórica adotada, este trabalho adota a formulação teóricometodológica de Duarte e Castro (2014a, 2014b), que, no âmbito do grupo da pesquisa Comunicação Televisual (COMTV), da Universidade Federal de Santa Maria, propõe um encaminhamento compatível com a proposta semiótica greimasiana.

Assim, levando em conta os processos comunicativo e discursivo, subjacentes ao texto e ao contexto, a proposta contempla três níveis de relação:

a) Nivel paratextual: entendimento das relações históricas, culturais, sociais, econômicas, políticas, tecnológicas, provenientes 
do contexto, e daquelas reconhecidas a partir do entorno comunicacional, envolvendo a observação na perspectiva da enunciação.

b) Nível intertextual: consideração pelas relações existentes entre o texto analisado e outros textos que lhe servem de modelo. Em um primeiro momento, podem ser identificadas as estratégias intertextuais de caráter paradigmático, ou seja, as semelhanças e dessemelhanças que o texto contrai com seu modelo, reconhecendo o gênero ao qual pertence o texto, o subgênero que o atualiza e o formato em que se materializa. Em um segundo momento, podem ser apresentadas as estratégias intertextuais de caráter sintagmático, ou seja, aqueles textos que precedem ou sucedem o texto analisado, de acordo com sua colocação na grade.

c) Nível intratextual: reconhecimento das deliberações tomadas pelos enunciadores no que se refere à forma de contar a narrativa ou, mais precisamente, ao "como dizer": em um primeiro momento, é feita a descrição do texto televisual e, então, a análise dos dispositivos discursivos e expressivos, buscando entender as questões temática, figurativa, temporal, espacial, actorial, tonal, e as operações de linguagem que as manifestam.

De tal modo, para dar conta do objetivo deste estudo, contemplam-se três níveis de análise:

a) Paratextualidade enunciativa: recuperação específica da situação enunciativa de cada peça, envolvendo o detalhamento da relação enunciador/enunciatário, no tempo e espaço especificados, realçando sua inserção na grade e a repercussão daquele espaço junto ao telespectador.

b) Intratextualidade: reconhecimento das deliberações tomadas pelos enunciadores no que se refere à forma de contar a narrativa ou, mais precisamente, ao "como dizer", fazendo, inicialmente, a descrição da peça selecionada e, depois, o detalhamento dos dispositivos discursivos e expressivos, relativamente aos elementos temáticos, figurativos, actoriais, temporais, espaciais, tonais, e às operações de linguagem que os manifestam.

c) Intertextualidade sintagmática: consideração das relações que o texto analisado mantém com outros programas da emissora, ou seja, com os textos que o precedem e/ou sucedem, de acordo com a disposição na grade, evidenciando as estratégias mais recorrentes.

Assim, o artigo busca responder aos objetivos e dar continuidade aos estudos da semiótica discursiva, sobretudo no que se refere ao fazer televisual.

\section{INSTÂNCIA ANALÍTICA}

Pela política da TV Globo de, costumeiramente, lançar nova programação no início do mês de abril, é em março que os produtos que comunicam ao telespectador essas novidades são veiculados; é 
quando, de fato, o povo brasileiro, passados os festejos carnavalescos e as férias escolares, recomeça sua rotina. A emissora busca surpreender o telespectador, nesse momento de retomada, com a veiculação de peças específicas que apresentam as inovações do segmento dentro da grade de programação (Souza, 2015, p. 74).

Hoje, diferentemente do que ocorria, é comum assistir a qualquer programa em aparelhos individuais, e no horário que melhor convier. Essa nova realidade tem trazido preocupação às emissoras de maneira geral, tendo em vista a nova configuração do telespectador: um consumidor mais exigente, com disponibilidade variada de informações e demanda por qualidade cada vez maior. A consequência natural é que, não obstante, os novos tempos têm acarretado à TV Globo perda de audiência em horários até então consolidados. Isso faz que a emissora busque constantemente a adoção de novas estratégias de comunicação para diferenciar-se, com vistas a garantir a atenção do telespectador e melhorar a pontuação de audiência.

Por isso, com o passar dos anos, a emissora sentiu a necessidade de criar diferentes formatos de manifestação discursiva, chegando, por fim, à realização de eventos com o propósito de lançar a nova programação.

\section{Paratextual enunciativo}

Em 2013, mais uma vez em busca de inovação, a empresa propôs divulgar a nova grade como um verdadeiro acontecimento, incluindo nova denominação (Vem $A \hat{l}$ ), veiculação de campanha com peças próprias (teasers, comerciais, quadros) e exibição de um programa especial, de uma hora, em comemoração ao lançamento da programação do ano.

A criação do novo programa coincide com a contratação de Sergio Valente, ex-presidente da agência de comunicação DM9DDB, para o cargo de diretor da Central Globo de Comunicação, com a missão de, nas palavras de Carlos Henrique Schroeder (Balieiro, 2013), diretor geral da TV Globo, “desenvolver uma comunicação mais efetiva com o público digital".

Além da contratação do novo diretor de comunicação, o conjunto de estratégias utilizadas pela emissora nessa veiculação compreende: criação de um programa exclusivo para divulgar a nova programação, reunindo, concomitantemente, entretenimento, ficção, informação e esporte; participação de diferentes atores sociais (atores, apresentadores, comentaristas e jornalistas) para apresentar cada atração; utilização de imagens inéditas que deverão compor os novos programas da emissora; emprego da trilha sonora tema de cada programa, para auxiliar na identificação do produto; sobreposição de logotipos de programas e, principalmente, ênfase à marca da TV Globo; referência à quantidade de atrações mantidas na grade; e convocação de diferentes segmentos e atores para comemorar o lançamento da nova programação.

A TV Globo, em 2013 - ao utilizar o espaço de um programa e linguagem específica para a divulgação da nova programação, misturando a riqueza de personagens e atrações, a qualidade técnica de suas produções, a capacidade estrutural convocada no programa e, num mesmo cenário, os diferentes segmentos de atuação -, surpreende o telespectador, sensibilizando-o e convocando-o a participar da 
grande festa, produzida pela TV Globo, para o lançamento da nova programação.

\section{Intratextual}

\section{Descrição do produto}

O formato escolhido para análise foi a peça gravada em São Paulo, no Credicard Hall, em 27 de março de 2013, e veiculado na quinta-feira, 28 de março, após a telenovela Salve Jorge, das $21 \mathrm{~h}$, sob a direção de José Bonifácio Brasil de Oliveira (Boninho), diretor de núcleo da emissora.

Vem Aí na Globo (2013) pertence ao subgênero programa, pois ocupa espaço autônomo na grade, com duração aproximada de 60 minutos e finalidade de divulgar a programação e projetar a emissora, com vistas à adesão do telespectador aos produtos a serem apresentados.

Em termos estruturais, o programa é composto de quatro blocos, separados por intervalos comerciais, que, aparentemente, contêm a mesma lógica. Cada bloco compõe-se de quadros diferenciados: locução de atores da emissora, em close; números musicais, sobretudo com os intérpretes que atuam nos programas da emissora, e que se exibem ao vivo, nos palcos que integram o cenário; e vídeos, apresentados em grande telão ao fundo do palco, que explicitam cenas inéditas de minisséries, seriados, telenovelas, entre outros. No conjunto, o programa assemelha-se a um grande show de variedades, de caráter híbrido, na medida em que se misturam atores reais e ficcionais, atores sociais e âncoras, atores sociais e intérpretes musicais, apresentação de vídeos e encenação de palco.

Outrossim, a escolha da locação para gravação do programa, na cidade de São Paulo, não é por acaso: pelo fato de a TV Globo ter sede na cidade do Rio de Janeiro e, por conseguinte, ser considerada emissora carioca, é na cidade de São Paulo, a maior do Brasil, que a emissora mais perde audiência. Por isso, a escolha da locação é estratégica: no intuito de aproximar a emissora do público paulista, a TV Globo escolhe, para a realização de um de seus principais eventos, a cidade de São Paulo.

Além disso, o programa explicita o grande aparato tecnológico, representado pela apresentação de números musicais, pelas inserções de vídeos no telão, pelo jogo de luzes, pela quantidade de câmeras, pela composição dos cenários e pela disposição da plateia, com a finalidade, mais uma vez, de causar impacto no telespectador. No fechamento, foi recuperado o jingle da abertura, criado por Sergio Valente e arranjo do diretor musical Ricardo Leão, cantado pelos vários artistas da emissora, reunidos no palco e acompanhados pela plateia.

\section{Dispositivos discursivos e expressivos}

a) Tematização: A narrativa reitera em todos os quadros o tema da celebração da emissora, ao reunir atores e apresentadores com o telespectador em uma grande festa para divulgar a nova programação da TV Globo para 2013, incluindo a retomada de alguns programas e atividades e o lançamento de outros, que passam a integrar a grade da emissora a partir de $1^{\circ}$ de abril. A comemoração fica explícita na fala inicial do ator Tony Ramos ("Hoje é um dia de festa, de uma grande festa para todos nós que trabalhamos na Globo e para você que nos assiste todos os 
dias. Hoje é um dia para celebrarmos, celebrarmos com você, a programação da Globo para 2013”); na referência aos seriados, feita por seus protagonistas; na apreciação do produto televisual referenciado pela emissora; na ênfase à equipe qualificada de seu elenco; e no constante aprimoramento em recursos tecnológicos. Em relação aos dispositivos expressivos, todas as falas dos atores remetem à preocupação da emissora com a qualificação de seus produtos, seja nas tomadas em close e panorâmicas, seja na exposição dos bastidores de produção e edição, seja no cuidado com cenários e figurinos, seja nas alternâncias cromáticas efetuadas, seja na articulação das linguagens sonoras e visuais ao longo da narrativa. A trilha sonora, construída especialmente para ser o tema do programa, enaltece, na sua letra, os segmentos de atuação da emissora e os programas produzidos, deixando em evidência a intenção da emissora de cativar a audiência do telespectador.

b) Figurativização: O programa se vale de atores de prestígio e renome, para conferir credibilidade ao tema, além de recorrer às equipes qualificadas de jornalismo, esporte e dramaturgia, exibir cenas inéditas que vão integrar os programas da emissora e fazer referência implícita ao apuro tecnológico que imprime em suas edições. No que concerne aos dispositivos expressivos, o programa articula com adequação as linguagens sonoras e visuais, faz uso de alternâncias cromáticas, confere destaque à trilha sonora e aos efeitos musicais, como se pode perceber na inserção de cantores nos quadros musicais e na diversidade de cantores convocados para interpretar a música tema do programa. Também se evidenciam movimentos e enquadramentos de câmera, jogo de luzes, sobreposição de imagens e sons, que imprimem o ritmo do programa.

c) Actorialização: O ator principal é a TV Globo, que, no programa, é representado na fala de atores, apresentadores, profissionais da emissora mais conhecidos pelo público, nos diferentes segmentos de atuação da empresa (jornalismo: William Bonner, Pedro Bial, Renata Vasconcellos, Tadeu Schmidt, Tiago Leifert, entre outros; esporte: Galvão Bueno, Walter Casagrande Júnior, Ronaldo Nazário, Arnaldo Cezar Coelho etc; dramaturgia: Tony Ramos, Marco Nanini, Marieta Severo, Deborah Secco, Glória Menezes, Andréa Beltrão, Fernanda Torres, entre outros; cantores: Daniel, Claudia Leitte e Carlinhos Brown; variedades: Luciano Huck, Angélica, Ana Maria Braga, Jô Soares, Xuxa, Fátima Bernardes, Regina Casé, Fernanda Lima e Serginho Groisman); na interpretação dos cantores que compõem o júri do programa The Voice Brasil, e que aqui comandam o quadro musical; na plateia, composta em sua maioria por dirigentes da empresa, profissionais, atores e seus familiares, aqui presentes para reforçar o programa exibido. Em relação aos dispositivos expressivos, o programa recorre ao plano close, para destacar os atores; alterna tomadas em close com o plano geral, para mostrar a interação com a plateia; combina de forma adequada a linguagem sonora e visual, na medida em que os personagens da dramaturgia são apresentados com a música tema de seu programa ao fundo; dá atenção especial ao figurino, daqueles que representam a emissora no palco. De maneira geral, a referência à emissora é também reiterada no conhecido 
"plim-plim", no reforço permanente à marca e no constante chamamento do telespectador para as atrações da emissora.

d) Temporalização: O programa tem duração de uma hora, dividido em quatro blocos, cada um deles com quadros variados. Na sua exibição, prioriza os segmentos da emissora (jornalismo, esportes, dramaturgia e variedades), e não a sequência na grade. Quanto ao tempo de alusão, o programa situa-se no presente, fazendo referências a episódios do passado, e projetando a grade a ser exibida naquele ano. Quanto aos dispositivos expressivos, articula linguagens sonoras e visuais, enfatizando cenários e figurinos, alternâncias cromáticas e composição musical. Nos trailers exibidos, adotam-se técnicas de captação da imagem que reforçam o movimento acelerado e o ritmo das cenas.

e) Espacialização: O programa desenvolve-se em um amplo palco, que dá o pano de fundo de quase todo o programa, com passarelas, que permitem a circulação dos apresentadores e, inclusive, facilitam a transição de um apresentador da plateia para o palco. Os trailers veiculados transitam entre ambientes internos e externos, de acordo com a narrativa dos programas, com vistas a aproximar o telespectador, familiarizando-o com os espaços em que acontecem os episódios. Em relação aos dispositivos expressivos, o cenário do programa é predominantemente escuro, para separar o palco da plateia e permitir a exibição dos trailers no telão. Em alguns momentos, esse espaço é enriquecido por alternâncias cromáticas, para ressaltar atores, figurinos, cenários e, até, o nome do programa. Quanto aos planos de câmera, há alternância permanente entre os planos gerais, americanos e closes.

f) Tonalização: Referente às estratégias de tonalização, ao anunciar os lançamentos e reforçar os segmentos da emissora, o programa faz uso de valores tonais que destacam a exaltação, em detrimento da moderação, quando os atores/apresentadores enaltecem a grande festa produzida para comemorar com o telespectador as novas produções, realçando a qualidade do quadro funcional, o nível de suas produções, a preocupação com valores sociais e o constante investimento em tecnologia. Também convoca os valores de emoção, em detrimento da racionalidade, caracterizada, por exemplo, na fala dos atores de A Grande Família, que relembram os treze anos de atuação conjunta, dos personagens e do convívio permanente; os valores da alegria, em detrimento da tristeza, manifestados na fala, nas expressões e nos gestos dos apresentadores. Em relação aos dispositivos expressivos, o tom principal é assegurado pela articulação das linguagens sonora e visual, pela rápida troca de imagens das câmeras, pelo uso de variações cromáticas, pela qualidade da fotografia, expressando os contrastes entre o cenário do evento e os trailers exibidos. Todos esses recursos são fortalecidos pelo arranjo agitado e alegre da música.

\section{Intertextual sintagmático}

Para compor a narrativa do texto em estudo, são convocadas novas e antigas atrações da emissora, ou seja, os antigos programas que continuam fazendo parte da grade da emissora, e também os novos 
programas, com o intuito de apresentar a programação, familiarizar o público com as novas atrações, reforçar a nova grade para aquele ano e, sobretudo, programar o telespectador para o que vai acontecer. Nessa construção, predominam estratégias de várias ordens, que se manifestam através dos seguintes movimentos:

\section{Metadiscursividade ou encadeamento recursivo}

Metadiscursividade é um recurso intertextual que atualiza outro discurso que o precede e que, ao mesmo tempo, é condição de sua existência (Castro, 2007). Pode ser manifestado por alguns movimentos como chamamentos de outros textos para dentro do texto em questão, indicação de resposta ao quadro anterior, alusão a outros textos etc. No show, são identificadas duas estratégias distintas:

a) Convocação de apresentadores, atores e jornalistas como reforço de cada segmento apresentado: o ator Leandro Hassum comenta o assalto simulado na sequência do programa, evidenciando a referência às novas séries $A$ Teia e $O$ Dentista Mascarado; Marco Nanini e Marieta Severo, protagonistas de A Grande Família, falam sobre a nova temporada; Renata Vasconcellos, do Fantástico, vira a cadeira do The Voice Brasil; Ronaldo Nazário vira a cadeira do The Voice Brasil, enquanto é tocada a música "Esse Cara Sou Eu", tema da novela Salve Jorge, telenovela exibida antes do programa; o apresentador Tiago Leifert conversa com Carlinhos Brown a respeito da nova temporada do The Voice Brasil, enquanto, ao fundo do palco, no telão, aparece a marca do programa e a música tema; o humorista Marcelo Adnet comenta sobre a falta que as novelas fariam, relembrando algumas que já foram veiculadas e falando das novas de 2013, Flor do Caribe, Sangue Bom e Amor à Vida; os comentaristas Galvão Bueno, Reginaldo Leme, Luciano Burti e Rubens Barrichello falam das novidades da emissora para o segmento de Fórmula 1; Glenda Kozlowski faz referência, ao lado de Galvão Bueno, à cobertura dos esportes e das competições esportivas que a Rede Globo transmitirá; as atrizes Glória Menezes e Deborah Secco falam da nova temporada da série Louco por Elas; Tadeu Schmidt, jornalista e apresentador do Fantástico, apresenta os novos quadros do programa; é exibido um trailer do Profissão Repórter, com Caco Barcellos, e nele aparece o jornalista acompanhando a montagem do novo cenário do Fantástico; é exibido um filme, de aproximadamente 30 segundos, com a música tema do programa Criança Esperança ao fundo, e uma narração apresenta a edição do programa de 2013.

b) Alusão a antigos programas para reforçar a trajetória da emissora: o humorista Marcelo Adnet relembra algumas novelas, como Roque Santeiro, Sassaricando, Rainha da Sucata, Fera Ferida, Pedra sobre Pedra, A Gata Comeu, Que Rei sou Eu, entre outras, para falar das novas novelas de 2013, Flor do Caribe, Sangue Bom e Amor à Vida; os atores protagonistas do seriado Pé na Cova, Marília Pêra e Miguel Falabella, referindo-se a Odete Roitmam, filha deles na trama, falam que poderiam ter outras filhas e chamá-las de Carminha, Nazaré, Perpétua ou Maria de Fátima, personagens importantes de outras telenovelas da emissora, como Avenida Brasil, Senhora do Destino, Tieta e Vale Tudo, respectivamente. 


\section{Embaralhamento}

Embaralhamento é o recurso de superposição ou imbricamento entre realidade e ficção, confundindo autêntico e artificial (Castro, 2007). Pode ser manifestado por movimentos como alusão a fatos do real, fusão entre o real e o ficcional, menção a características reais da emissora junto ao telespectador, convocação explícita do leitor, entre outros. São identificadas quatro estratégias distintas:

a) Recorrência a fatos do real para programar o telespectador para as novidades da grade: o jornalista César Tralli refere-se à encenação de um acidente no palco e, ao mesmo tempo, faz alusão às coberturas jornalísticas da emissora; os apresentadores de esportes Arnaldo Cézar Coelho, Walter Casagrande Júnior e Galvão Bueno fazem referência ao cenário de estúdio, com os comentaristas Luís Roberto e Júnior, e ao cenário de estádio, com os comentaristas Caio Ribeiro e Cléber Machado, e apresentam o ex-jogador e agora comentarista Ronaldo Nazário. Além disso, mostram as inovações tecnológicas a serem utilizadas pela emissora, principalmente durante as transmissões ao vivo, como na Copa das Confederações, evento esportivo ocorrido em 2013; os comentaristas Galvão Bueno, Reginaldo Leme, Luciano Burti e Rubens Barrichello falam das novidades da emissora para o segmento de Fórmula 1.

b) Encenação de episódios que embaralham realidade e ficção para atrair a atenção do telespectador: o ator Luís Carlos Miele explica o que é o programa Vem Aí e é interrompido por uma simulação de assalto, que se refere ao seriado A Teia, do qual Miele integra o elenco; os atores principais de A Grande Família, Marco Nanini e Marieta Severo, falam sobre o programa, misturando e divertindose com os planos da realidade e da ficção, os treze anos de relação entre Lineu e Nenê, o casamento dos personagens e a parceria dos atores.

c) Aproximação do telespectador por meio de menção a características reais da emissora: a abertura evidencia o nome do programa, em caixa baixa: "vem á́". A tela ainda apresenta a marca da empresa, no canto esquerdo da tela, e a conhecida melodia "plim-plim”; o filme do jornalismo, narrado por William Bonner, explicita os bastidores das notícias e a estrutura por trás daquilo que é veiculado pela emissora; as transições de cenas estampam, na tela, o nome do programa e a marca da emissora; as novas contratações da emissora, Ronaldo Nazário e Rubens Barrichello, são apresentadas e, ao mesmo tempo, identificadas como pessoas dotadas de capacidade técnica que vêm somar nas transmissões e no quadro funcional da emissora.

d) Convocação explícita do público: a trilha sonora, além de fazer alusão a outros programas da emissora, constrói-se em torno de uma letra que convoca o público para a atração a ser exibida.

\section{Autorreflexividade ou reiteração de si próprio}

Autorreflexividade é o recurso de falar de si mesmo, reiterando marcas e ações (Castro, 2007). Pode ser manifestado por movimentos como alusão à nova programação, indicação das marcas da emissora, entre outros. São identificadas duas estratégias distintas: 
a) Alusão às novidades da programação: o ator Tony Ramos, no início do programa, explica que Vem Aí na Globo é uma grande festa para apresentar a programação anual da emissora; a trilha sonora é construída em torno de uma letra que convoca o público para a atração a ser exibida, bem como os programas da emissora; Luís Carlos Miele explica o programa Vem Aí, a natureza do que vai ser apresentado, os atores que estão no palco e os que estão na plateia, e todos que possibilitam a realização de bons programas pela emissora; Marco Nanini e Marieta Severo falam da nova temporada de A Grande Família; o humorista Marcelo Adnet relembra as novelas que já foram veiculadas pela emissora e apresenta as novas de 2013, Flor do Caribe, Sangue Bom e Amor à Vida; Miguel Falabella e Marília Pêra comentam as novidades do seriado Pé na Cova; a atriz mirim Mel Maia fala sobre o trabalho em telenovelas e apresenta Saramandaia e Joia Rara.

b) Indicação das marcas da emissora: o humorista Marcelo Adnet aparece sentado em uma cadeira, colocada diante de um aparelho televisor, que possui a marca da Rede Globo; o nome do programa, para marcar o início de um quadro, aparece na tela.

É assim, no nível intertextual, que a emissora mais apela para a tensão entre as ofertas inovadoras e aquelas já existentes na grade, envolvendo bastidores, notícias, acontecimentos e curiosidades. Essa tensão entre inovação e tradição é o principal movimento da emissora para valorizar os produtos bem-sucedidos da grade e preparar as novidades planejadas. Seja recorrendo a discursos veiculados, seja embaralhando mundos, seja falando de si mesma, a Rede Globo ressalta a plurirrealidade de que a emissora lança mão, reforçando o caráter nitidamente autopromocional da iniciativa.

\section{APONTAMENTOS FINAIS}

Ao retomar o objetivo do trabalho, centrado no exame do texto Vem Aí na Globo 2013, enunciado pela TV Globo, e assim refletir sobre as estratégias comunicativas e discursivas adotadas pela empresa ao utilizar novos e antigos programas da grade para construir um novo produto televisual e cativar o telespectador, é possível fazer algumas considerações.

No que diz respeito à natureza da televisão brasileira e sua relação com a publicidade, percebe-se que a promocionalidade (Castro, 2012) invade os intervalos e os espaços dos programas. A televisão "vive da venda de cada minuto de programação, isto é, transforma em valor comercial seu tempo de emissão. Para cada minuto existe um investimento, um preço, uma tabela e, sobretudo, um lucro" (Marcondes Filho, 1988, p. 18). Na verdade, a promocionalidade, por dizer respeito a tudo que é feito em televisão, ultrapassa os espaços restritos ao break comercial, invade a grade de programação e chega até a contaminar as ações comandadas pela emissora. Tudo que é feito em televisão precisa, necessariamente, ser alardeado, divulgado, projetado, confirmando Eco (1984), para quem a televisão não fala de nada sem antes falar de si mesma, o que caracteriza o discurso autopromocional.

No que tange à análise semiótica do programa Vem Aí na Globo 2013, percebe-se que a emissora confia a diferentes atores sociais o papel de enunciador da mensagem. São atores, jornalistas, comentaristas, 
apresentadores e âncoras que, no papel de emissores da mensagem, assumem a posição da empresa e anunciam as novidades da grade para aquele ano. Essa estratégia de ressignificação do sujeito enunciador dota esses distintos atores dos valores da TV Globo, que buscam reforçar sua imagem, consolidar seus produtos e, principalmente, estabelecer relação de proximidade com o público telespectador, garantindo, assim, simpatia, adesão e fidelidade, para mantê-la como referência em televisão aberta no Brasil.

Ainda em relação às inovações empreendidas pela emissora, na última década a TV Globo reservou, em sua programação, maior espaço para a veiculação de materiais específicos para divulgar a programação anual. Em questão de tempo, as peças variam de um minuto a uma hora de duração, sendo que no programa Vem Aína Globo, diferentemente de todas as outras peças já veiculadas, houve forte campanha publicitária que a precedeu, reiterando, ao longo de toda a programação, em uma estratégia totalmente inovadora, o programa criado para "cativar o telespectador".

Após a análise discursiva, fica evidente a remissão feita, repetidas vezes, ao The Voice Brasil. Em 2013, foi veiculada a segunda temporada do reality show musical que pretende descobrir a "nova voz do Brasil"; como, em 2012, o programa teve grande repercussão e audiência, muitos programas são embaralhados e fazem referência a ele. O mesmo cenário ambienta os segmentos de jornalismo, esporte e telenovela. Aliás, Boninho, o diretor de Vem Aí, também é o responsável pela atração musical.

Vem Aí na Globo 2013 dialoga com todos os programas da TV Globo e convoca todo seu elenco para comemorar, em uma grandiosa produção, as inovações da grade para aquele ano, evidenciando, desde o início, a produção de uma grande festividade, para celebrar com o telespectador a nova programação, aproximando ainda mais a emissora do telespectador. Quanto ao papel do telespectador, ele é projetado discursivamente na convocação feita pelo jingle "nosso programa é cativar você" e no chamamento feito pelo ator Tony Ramos na abertura "Hoje é um dia de festa, de uma grande festa para todos nós que trabalhamos na Globo e para você que nos assiste todos os dias. Hoje é um dia para celebrarmos, celebrarmos com você, a programação da Globo para 2013”.

Além das marcas da emissora (logotipos e trilhas) e das marcas dos produtos (logotipos, trilhas, cenários e atores), são glorificadas as características técnicas da emissora: quantidade de filiais, área de abrangência, alcance nacional, audiência e produção, além do constante investimento em tecnologia, reiterando e exaltando, em todos os produtos, o padrão Globo de qualidade, criado na década de 1970.

Percebe-se que, mesmo com o atual cenário de constante queda de audiência de todas as emissoras do país, a Globo continua mantendo sua liderança. E para isso, uma de suas apostas é, na fala de si mesma, o movimento permanente entre ofertas inovadoras e reiteração daquelas já consolidadas na grade. Se, até então, eram comuns intervalos comerciais, quadros ou referências explícitas em programas para falar da emissora, Vem aí na Globo constitui um novo desafio: reúne as características de show de variedades, de verdadeiro espetáculo gravado em palco especial, com a presença de público selecionado. É a grande novidade da emissora para o ano, com vistas à permanência no primeiro lugar do ranking das emissoras do país. 


\section{REFERÊNCIAS}

BALIEIRO, S. Sergio Valente deixa a DM9DDB e vai para a TV Globo. Época Negócios, 17 jan. 2013. Disponível em: http://glo.bo/2ewpqk5. Acesso em: 31 out. 2016.

CASTRO, M. L. D. Do gênero ao formato promocional televisual. In: DUARTE, E. B.; CASTRO, M. L. D. (Org.). Comunicação audiovisual: gêneros e formatos. Porto Alegre: Sulina, 2007. p. 117-139.

. Em torno de uma gramática do promocional em televisão. In: SILVEIRA, A. C. M. et al. (Org.). Estratégias midiáticas. Santa Maria: Facos, 2012. p. 115-127.

DUARTE, E. B. Televisão: desafios teórico-metodológicos. In: BRAGA, J. L.; LOPES, M. I. V.; MARTINO, L. C. (Org.). Pesquisa empírica em comunicação. São Paulo: Paulus, 2010. p. 227-248

DUARTE, E. B.; CASTRO, M. L. D. Produção midiática: o ir e vir entre teoria, metodologia e análise. In: BARICHELLO, E. M. M. R.; RUBLESCKI, A. S. Pesquisa em comunicação: olhares e abordagens. Santa Maria: Facos, 2014a. p. 67-87.

. Da teoria à aplicação: detalhamento metodológico. Material didático PPGCOM/ UFSM, Porto Alegre, 2014b.

ECO, Umberto. Viagem na irrealidade cotidiana. Rio de Janeiro: Nova Fronteira, 1984.

GREIMAS, A. J; COURTES, J. Dicionário de semiótica. São Paulo: Contexto, 2013.

HJELMSLEV, L. Prolegômenos a uma teoria da linguagem. São Paulo: Perspectiva, 2013.

MARCONDES FILHO, Ciro. Televisão: a vida pelo vídeo. São Paulo: Moderna, 1988.

SOUZA, G. Vem aí na Globo: estratégias de divulgação da programação. 2015. Dissertação (Mestrado) - Universidade Federal de Santa Maria, Santa Maria, 2015. 